\title{
BMJ Open Toxicoepidemiology of poisoning exhibited in Indian population from 2010 to 2020: a systematic review and meta-analysis
}

Chaitanya Mittal, ${ }^{1}$ Surjit Singh (D) ${ }^{2}$ Praveen Kumar-M, ${ }^{3}$ Shoban Babu Varthya (D) ${ }^{2}$

To cite: Mittal C, Singh S, Kumar-M P, et al.

Toxicoepidemiology of poisoning exhibited in Indian population from 2010 to 2020: a systematic review and meta-analysis. BMJ Open 2021;11:e045182. doi:10.1136/ bmjopen-2020-045182

- Prepublication history and additional supplemental material for this paper are available online. To view these files, please visit the journal online (http://dx.doi.org/10.1136/ bmjopen-2020-045182).

CM, SS and SBV contributed equally.

$\mathrm{CM}$ and SS are joint first authors.

Received 12 0ctober 2020

Revised 20 April 2021

Accepted 07 May 2021

D Check for updates

(C) Author(s) (or their employer(s)) 2021. Re-use permitted under CC BY-NC. No commercial re-use. See rights and permissions. Published by BMJ.

${ }^{1}$ Forensic Medicine and Toxicology, AllMS Jodhpur, Jodhpur, India

${ }^{2}$ Pharmacology, AllMS Jodhpur, Jodhpur, India

${ }^{3}$ Pharmacology, Post Graduate Institute of Medical Education and Research, Chandigarh, India

Correspondence to Dr Shoban Babu Varthya; drshobanpgimer@gmail.com

\section{ABSTRACT}

Objective To determine the prevalence of pesticide, corrosive, drugs, venom and miscellaneous poisoning in India.

Setting Systematic literature search was done in PubMed Central, Cochrane and Google Scholar databases for studies that satisfied the inclusion criteria. Systematic review and meta-analyses of all observational studies published in the English language from January 2010 to May 2020 were included in this review.

Participants Patients exposed to poisoning reported to hospitals were included.

Primary and secondary outcome measures The prevalence of pesticide poisoning was analysed. The prevalence of poisoning due to corrosives, venom, drugs and miscellaneous agents, along with subgroup analysis based on age and region, was also determined. The percentage of persons with poisoning along with $95 \% \mathrm{Cl}$ was analysed.

Results Pooled analysis of studies revealed that pesticides were the main cause of poisoning in adults, with an incidence of $63 \%$ (95\% Cl $63 \%$ to $64 \%)$, while miscellaneous agents were the main cause of poisoning in children, with an incidence of $45.0 \%$ (95\% Cl $43.1 \%$ to $46.9 \%$ ), among those presenting to hospitals. Pesticide poisoning was the most prevalent in North India $(79.1 \%$, $95 \% \mathrm{Cl} 78.4 \%$ to $79.9 \%)$, followed by South $(65.9 \%, 95 \%$ Cl $65.3 \%$ to $66.6 \%)$, Central $(59.2 \%, 95 \%$ Cl $57.9 \%$ to $60.4 \%)$, West $(53.1 \%, 95 \% \mathrm{Cl} 51.9 \%$ to $54.2 \%)$, North East (46.9\%, 95\% Cl $41.5 \%$ to $52.4 \%$ ) and East (38.5\%, 95\% Cl $37.3 \%$ to $39.7 \%$ ). The second most common cause of poisoning was miscellaneous agents $(18 \%, 95 \% \mathrm{Cl} 18 \%$ to $19 \%)$, followed by drugs $(10 \%, 95 \% \mathrm{Cl} 10 \%$ to $10 \%)$, venoms (6\%, $95 \% \mathrm{Cl} 6 \%$ to $6 \%)$ and corrosives $(2 \%, 95 \%$ Cl $1 \%$ to $2 \%$ ).

Conclusions Pesticide poisoning is the most common type of poisoning in adults, while miscellaneous agents remain the main cause of poisoning in children. PROSPERO registration number CRD42020199427.

\section{INTRODUCTION}

A poison is a substance that is capable of causing illness or harm to a living organism on contact or upon introduction to the body. Toxins and venoms are poisons of biological origin, with the latter usually reserved to
Strengths and limitations of this study

- More than 50000 participants from 134 studies were included in this study to evaluate the type and manner of poisoning and their prevalence rates in the Indian population from January 2010 to May 2020.

- Age-wise and region-wise distributions of the prevalence of poisoning were also analysed.

- The analysis identified research gaps in patients' medical outcomes.

- Limitations include the results of the review being drawn from analysis of observational studies.

describe bites or stings of a poisonous animal. Over the past decade, poisoning has become an increasing cause for concern not only in India but globally. ${ }^{1}$

In 2016, deaths due to suicide were around 800000 worldwide, implying an annual world suicide rate of 10.5 per 100000 population. However, in India the suicide rate is almost double (18.5 suicide deaths for 100000 population). Majority (79\%) of suicides occur in low-income and middle-income countries. Ingestion of poison is one of the most common modes of suicide in low-income and middle-income countries such as India. ${ }^{2}$ Among poisons, pesticides contribute to majority of cases of poisoning in India. ${ }^{3}$ Pesticide poisoning in India is highly prevalent due to the widespread use of pesticides for agricultural and household activities. Other poisoning agents include household agents, envenomation and drugs. It is observed that agricultural or household pesticides and drugs are taken intentionally, whereas intake of corrosives, kerosene and other miscellaneous agents as well as animal bites happen accidentally. ${ }^{4}$

The WHO estimated that death due to envenomation is around 100000 annually, and around three times the people who 
survived were disabled due to amputation and incomplete recovery. Approximately half of these deaths were reported in India due to the natural existence of different poisonous species such as snakes, scorpions and spiders in the country. In this regard, the WHO initiated a strategy to prevent and control snakebite-related deaths and disability. ${ }^{6}$

Aggravating or predisposing factors in emerging countries like India vary from financial stress to psychiatric illness, along with sociocultural practices such as the patriarchal system. The patriarchal system makes women more financially dependent on men, increasing their risk of suicide. ${ }^{7-9}$

The pattern of poisoning varies between geographical regions of the country. Understanding the geographical pattern of poisoning in a country helps in the identification of risk factors. This, along with the integration of preventive and promotive health services, may help reduce morbidity and mortality. ${ }^{10}$

Due to lack of comprehensive scientific data on the prevalence of poisoning and its variation with age and region, preventive, curative and rehabilitation measures are poorly implemented in India. Therefore the present systematic review and meta-analysis was done to study the prevalence of various types of poisoning in India and their variation with age and region.

\section{MATERIALS AND METHODS \\ Protocol and registration}

The study protocol was registered with PROSPERO (International Prospective Register of Systematic Reviews; available as Shoban Babu Varthya et $a l .{ }^{11}$

\section{Methods}

In this review, we surveyed and evaluated various observational studies on the prevalence of poisoning across India. Pesticides, corrosives, venoms, drugs and other miscellaneous agents were regarded in this review analysis as poisons.

\section{Eligibility criteria}

To analyse the prevalence of poisoning, studies with participants exposed to acute poisoning, irrespective of outcome, were included in the analysis. We included observational studies (retrospective/prospective/crosssectional) published in the English language between the years 2010 and 2020, with prevalence of poisoning in India as the endpoint. This analysis helps generate the overall prevalence of poisoning in India and their variation with age and region.

\section{Information sources}

A literature search was done using MeSH terms such as 'prevalence', 'poison', 'poisoning', 'pesticides', 'organophosphate', 'corrosives', 'drugs' and 'India' in three databases (PubMed Central, Cochrane and Google
Scholar). Additional studies were identified through cross-references of selected articles.

\section{Search}

The search strategy for PubMed is provided in online supplemental file 1. The last search was done in May 2020.

\section{Study selection and data collection process}

Studies were selected based on predefined eligibility criteria. All eligible articles were taken for further screening after removing duplicates and those unrelated to study inclusion criteria. Studies which were included after review of abstracts were evaluated by screening the full text. All data on authorship, year of publication, study design, study population (patients who ingested poisons), baseline characteristics (age, sex, marital status, educational status, type of family, etc), list of poisons included in the study, total study population, and any other relevant outcomes essential for data synthesis were extracted from the selected studies. Study selection and data collection were done by two authors independently and data were compiled after complete data retrieval. If any conflict exists a third author revised and resolved the conflict.

\section{Summary measures}

Data on prevalence were presented in percentages across age group and regions.

\section{Meta-analysis (quantitative synthesis)}

Dichotomous data, that is, the percentage of subjects with particular poisoning, were analysed and reported along with $95 \%$ CI. The meta-analysis of proportions was done using the $\mathrm{R}$ software, with the packages meta and metafor. The results of both the random effect model and the fixed effect model were calculated. The fixed effect model assumes that the between-study variance is zero, whereas the random effect model takes both within-study and between-study variances into account. If the heterogeneity is greater than $40 \%$, the results of the random effect model will be more representative of the data. To prevent underestimation of the size of the CI around the weighted average proportion and overestimation of the degree of heterogeneity across the observed proportions, we used Freeman-Tukey double arcsine transformation (DAT). This will help the data to conform to the normal distribution as much as possible, enhancing the validity and generalisability of statistical analyses.

Heterogeneity was estimated using tau $(\tau)$. Subgroup analysis was done to estimate whether there is a difference in the percentage of individuals who ingested pesticides with regard to geographical area and among children and adults. This was done with the assumption that there is a common between-study variance component across studies, thereby pooling the within-group estimates of $\tau^{2}$ estimated using the Freeman-Tukey DAT.

\section{GRADEpro analysis to assess quality of evidence}

The overall quality of evidence for each of the outcomes was assessed using GRADEpro GDT (Guideline 
Development Tool) software based on the principles of the Grading of Recommendations, Assessment, Development and Evaluation (GRADE) ${ }^{5}{ }^{12}$ GRADEpro does not recommend grading of evidence if the study is a singlegroup analysis. Hence no grading of evidence was done for the endpoint.

\section{Patient and public involvement}

There was no patient and public involvement in the study.

\section{RESULTS}

\section{Study selection}

An initial search of all databases yielded a total of 797 articles. After removal of duplicates, 626 articles remained, which were subjected to the inclusion and exclusion criteria. A thorough screening of the papers based on title and abstract reduced the search results to 214, and in the final analysis 134 articles were included. Among the excluded articles, there were 23 review articles, 2 pooled analyses, 21 articles on heavy metal poisoning, 23 articles on individual poisons other than pesticides, and in 8 articles full text was not available. The authors of three articles were contacted to request for access to specific data on poisoning, but these were not provided and hence the articles were excluded. Therefore, the final qualitative and quantitative syntheses were performed on 134 research articles. Figure 1 illustrates a flow chart of the various steps of the systematic review.

\section{Study characteristics}

The characteristics of the included studies are enumerated in table 1, and the description of each study along with the references can be found in online supplemental table S1a.

\section{Demographic distribution}

In terms of the manner of poisoning, the results show that suicidal poisoning was more common than accidental poisoning. The highest prevalence of poisoning was observed in persons in the 19-40 years age group (105 studies). The overall sex ratio was 1.7 , and the male to female ratio was highest in the northern region (2.35) and lowest in the eastern region (1.28).

\section{Agents responsible for poisoning}

We have broadly classified poisons into five categories: pesticides, corrosives, venoms, drugs and miscellaneous

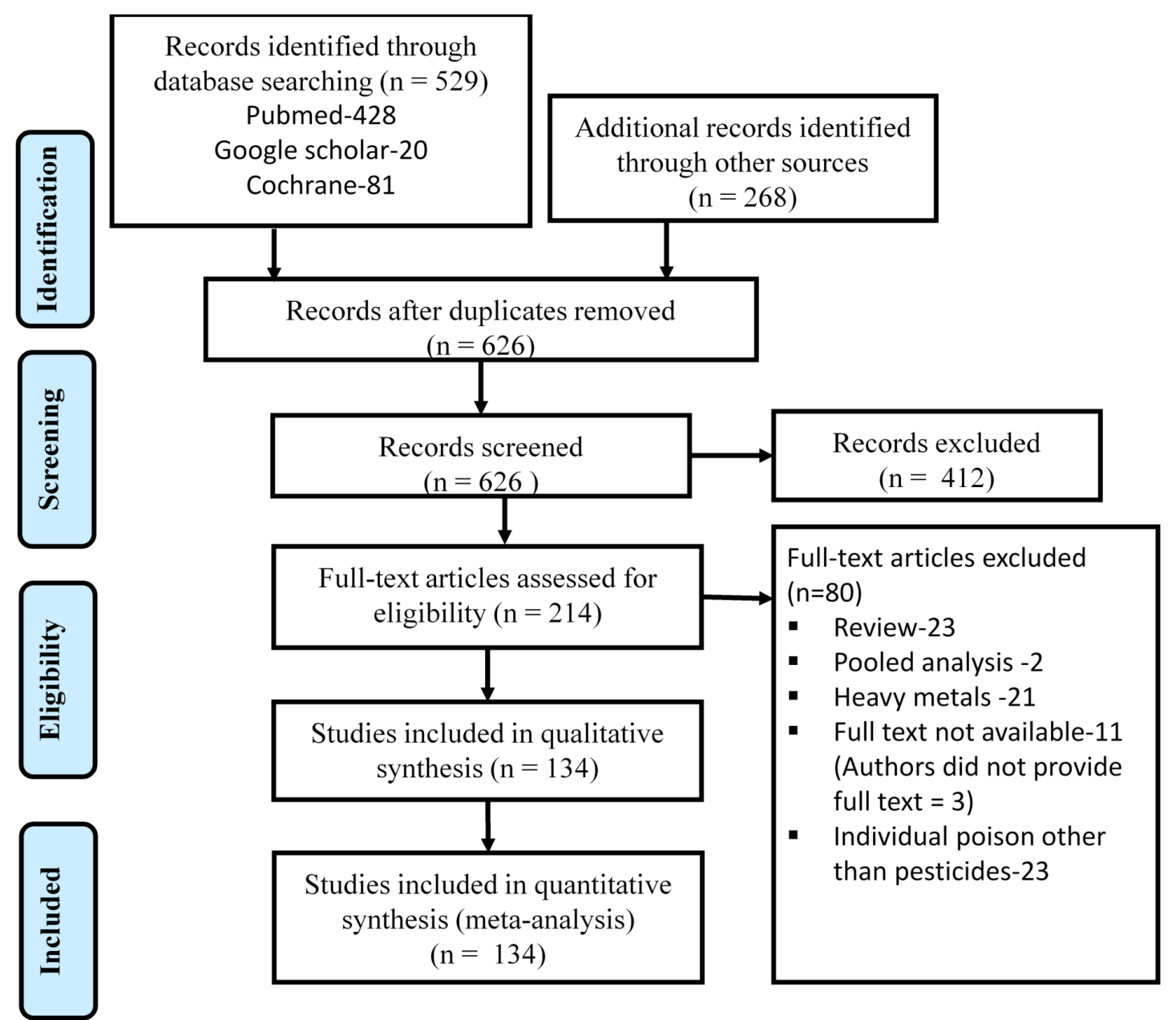

Figure 1 PRISMA flow chart of selection of studies for systematic review. PRISMA, Preferred Reporting Items for Systematic Reviews and Meta-Analyses. 
Table 1 Baseline characteristics of study population included in the analysis

\begin{tabular}{ll}
\hline Study characteristics & $\begin{array}{l}\text { Percentage } \\
\text { of study } \\
\text { population }\end{array}$ \\
\hline $\begin{array}{l}\text { Type of studies }(N=134) \\
\text { Retrospective }(75)\end{array}$ & 56 \\
\hline Cross-sectional $(12)$ & 9 \\
\hline Prospective $(47)$ & 35 \\
\hline Regional distribution of study population & \\
\hline Central $(N=21, n=5854)$ & 11 \\
\hline East $(N=9, n=6684)$ & 13 \\
\hline North East $(N=2, n=330)$ & 1 \\
\hline North $(N=21, n=11628)$ & 22 \\
\hline South $(N=61, n=21212)$ & 40 \\
\hline West $(N=20, n=7123)$ & 13 \\
Male to female ratio & \\
\hline Central $(N=21, n=5854)$ & 1.51 \\
\hline East $(N=9, n=6684)$ & 1.28 \\
\hline North East $(N=2, n=330)$ & 1.66 \\
\hline North $(N=21, n=11561)$ & 2.35 \\
\hline South $(N=61, n=21279)$ & 1.77 \\
\hline West $(N=20, n=7123)$ & 1.87 \\
\hline India $(N=134, n=52$ 831) & 1.74 \\
\hline
\end{tabular}

Age-wise distribution

\begin{tabular}{ll}
$\leq 18$ years $(n=12642)$ & 26 \\
19-60 years $(n=34653)$ & 70 \\
$>60$ years $(n=2228)$ & 4 \\
Marital status $(N=62)$ & 65 \\
Married $(n=12$ 027) & 35 \\
Unmarried $(n=6499)$ & \\
Educational status $(N=31)$ & 70 \\
Literate $(n=5467)$ & 30 \\
Illiterate $(n=2373)$ & \\
Type of family $(N=13)$ & 41 \\
Nuclear $(n=1248)$ & 59 \\
Joint $(n=1780)$ & \\
Area-wise distribution $(N=80)$ & 62 \\
Rural $(n=15896)$ & 38 \\
Urban $(n=9726)$ & \\
Occupational distribution $(N=61)$ & 56 \\
Farmers $(n=9404)$ & 15 \\
Housewives $(n=2481)$ & 10 \\
Students $(n=1686)$ & 9 \\
Labourers $(n=1448)$ & 4 \\
Service $(n=609)$ & 4 \\
Unemployed $(n=704)$ & 2 \\
Self-employed $(n=385)$ & \\
\hline
\end{tabular}

Continued
Table 1 Continued

Study characteristics

Percentage

of study

population

\begin{tabular}{ll} 
Manner of poisoning $(\mathrm{N}=111)$ & \\
Suicidal $(\mathrm{n}=30652)$ & 71 \\
Accidental $(\mathrm{n}=11616)$ & 27 \\
Others $(\mathrm{n}=926)$ & 2 \\
\hline
\end{tabular}

$\mathrm{n}$, sample size; $\mathrm{N}$, total number of studies.

agents. Overall, pesticide poisoning stands to be more common in India and across regions, followed by miscellaneous agents $(18 \%)$, drugs $(11 \%)$ and venoms $(10 \%)$, and corrosives $(3 \%)$. Details of poisonous agent in each group are found in online supplemental table S1b.

\section{Study type}

Majority of the studies were retrospective observational studies (75 retrospective studies, 47 prospective studies, 12 cross-sectional studies).

\section{Outcomes}

The pooled data on the prevalence of various poisons are shown in table 2.

\section{Percentage of pesticide and corrosive poisoning}

Pooled analysis of studies revealed pesticides to be the main cause of poisoning in $63 \%$ (95\% CI $63 \%$ to $64 \%$; $\left.\mathrm{I}^{2}=100 \%, \mathrm{p}<0.01\right)$ of those presenting to hospitals, in the fixed effect model. In the random effect model, the prevalence of pesticide poisoning among individuals was around $62 \%$ (95\% CI $56 \%$ to $68 \%$ ) (online supplemental figure 1). In adults, pesticides were the main cause of poisoning in $65.3 \%$ (95\% CI $64.8 \%$ to $65.7 \%$ ) and $66.8 \%$ (95\% CI $61.4 \%$ to $71.9 \%)$ in the fixed effect and random effect models. In children, pesticides were responsible for $22.4 \%$ (95\% CI $20.7 \%$ to $24.0 \%$; $\mathrm{I}^{2}=100 \%, \mathrm{p}<0.01$ ) and $23.2 \%$ (95\% CI $11.4 \%$ to $37.6 \%$ ), in the fixed effect and random effect models, respectively (online supplemental figure 1). The prevalence of pesticide poisoning in Central, East, North East, North, South and West India was $59.2 \%$ (95\% CI $57.9 \%$ to $60.4 \% ; \mathrm{I}^{2}=99 \%, \mathrm{p}<0.01$ ), $38.5 \%$ (95\% CI $37.3 \%$ to $39.7 \%$; $\mathrm{I}^{2}=99 \%, \mathrm{p}<0.01$ ), $46.9 \%$ $\left(95 \%\right.$ CI $41.5 \%$ to $\left.52.4 \% ; \mathrm{I}^{2}=0 \%, \mathrm{p}=0.64\right), 79.1 \%(95 \% \mathrm{CI}$ $78.4 \%$ to $79.9 \% ; \mathrm{I}^{2}=100 \%, \mathrm{p}<0.01$ ), $65.9 \%$ (95\% CI $65.3 \%$ to $\left.66.6 \% ; \mathrm{I}^{2}=99 \%, \mathrm{p}<0.01\right)$ and $53.1 \%(95 \%$ CI $51.9 \%$ to $54.2 \%$; $\left.\mathrm{I}^{2}=99 \%, \mathrm{p}<0.01\right)$ in the fixed effect model analysis (online supplemental figure 1). The random effect results are shown in online supplemental figure 1. Pesticide poisoning was the most prevalent poisoning in North India, followed by South, Central, West, North East and East India.

Pooled analysis of studies revealed corrosives to be the cause of poisoning in $2 \%$ (95\% CI $1 \%$ to $2 \% ; \mathrm{I}^{2}=96 \%$, $\mathrm{p}<0.01)$ and $3 \%(95 \%$ CI $2 \%$ to $3 \%)$ of patients, using 
Table 2 Percentage of pooled data of various poisoning encountered in India

\begin{tabular}{|c|c|c|c|c|}
\hline Outcome & $\%$ of pooled data & $95 \% \mathrm{Cl}$ & $I^{2}(\%)$ & P-value* \\
\hline \multicolumn{5}{|c|}{ Percentage of pesticide poisoning } \\
\hline Overall & $\begin{array}{l}\text { FEM: } 63 \\
\text { REM: } 62\end{array}$ & $\begin{array}{l}63 \text { to } 64 \\
56 \text { to } 68\end{array}$ & 100 & $<0.01$ \\
\hline Adults & $\begin{array}{l}\text { FEM: } 65.3 \\
\text { REM: } 66.8\end{array}$ & $\begin{array}{l}64.8 \text { to } 65.7 \\
61.4 \text { to } 71.9\end{array}$ & 100 & $<0.01$ \\
\hline Children & $\begin{array}{l}\text { FEM: } 22.4 \\
\text { REM: } 23.2\end{array}$ & $\begin{array}{l}20.7 \text { to } 24.0 \\
11.4 \text { to } 37.6\end{array}$ & 94 & $<0.001$ \\
\hline \multicolumn{5}{|l|}{ Region-wise } \\
\hline Central & $\begin{array}{l}\text { FEM: } 59.2 \\
\text { REM: } 60.8\end{array}$ & $\begin{array}{l}57.9 \text { to } 60.4 \\
46.5 \text { to } 74.2\end{array}$ & 99 & $<0.01$ \\
\hline East & $\begin{array}{l}\text { FEM: } 38.5 \\
\text { REM: } 42.3\end{array}$ & $\begin{array}{l}37.3 \text { to } 39.7 \\
22 \text { to } 64\end{array}$ & 99 & $<0.01$ \\
\hline North East & $\begin{array}{l}\text { FEM: } 46.9 \\
\text { REM: } 47.5\end{array}$ & $\begin{array}{l}41.5 \text { to } 52.3 \\
8.2 \text { to } 88.8\end{array}$ & 0 & 0.64 \\
\hline North & $\begin{array}{l}\text { FEM: } 79.1 \\
\text { REM: } 56.4\end{array}$ & $\begin{array}{l}78.4 \text { to } 79.9 \\
42 \text { to } 70\end{array}$ & 100 & $<0.01$ \\
\hline South & $\begin{array}{l}\text { FEM: } 65.9 \\
\text { REM: } 68.6\end{array}$ & $\begin{array}{l}65.3 \text { to } 66.6 \\
60 \text { to } 76\end{array}$ & 99 & $<0.01$ \\
\hline West & $\begin{array}{l}\text { FEM: } 53.1 \\
\text { REM: } 58.6\end{array}$ & $\begin{array}{l}51.9 \text { to } 54.2 \\
43.9 \text { to } 72.6\end{array}$ & 99 & $<0.01$ \\
\hline
\end{tabular}

\section{Percentage of corrosive poisoning}

\begin{tabular}{|c|c|c|c|c|}
\hline Overall & $\begin{array}{l}\text { FEM: } 2 \\
\text { REM: } 3\end{array}$ & $\begin{array}{l}1 \text { to } 2 \\
2 \text { to } 3\end{array}$ & 96 & $<0.01$ \\
\hline Adults & $\begin{array}{l}\text { FEM: } 1.3 \\
\text { REM: } 1.7\end{array}$ & $\begin{array}{l}1.1 \text { to } 1.4 \\
1.1 \text { to } 2.5\end{array}$ & 95 & $<0.01$ \\
\hline Children & $\begin{array}{l}\text { FEM: } 10.8 \\
\text { REM: } 11.2\end{array}$ & $\begin{array}{l}9.6 \text { to } 12 \\
7.2 \text { to } 15.8\end{array}$ & 91 & $<0.01$ \\
\hline
\end{tabular}

Percentage of venom poisoning
Overall

FEM: 6

REM: 3

Region -wise

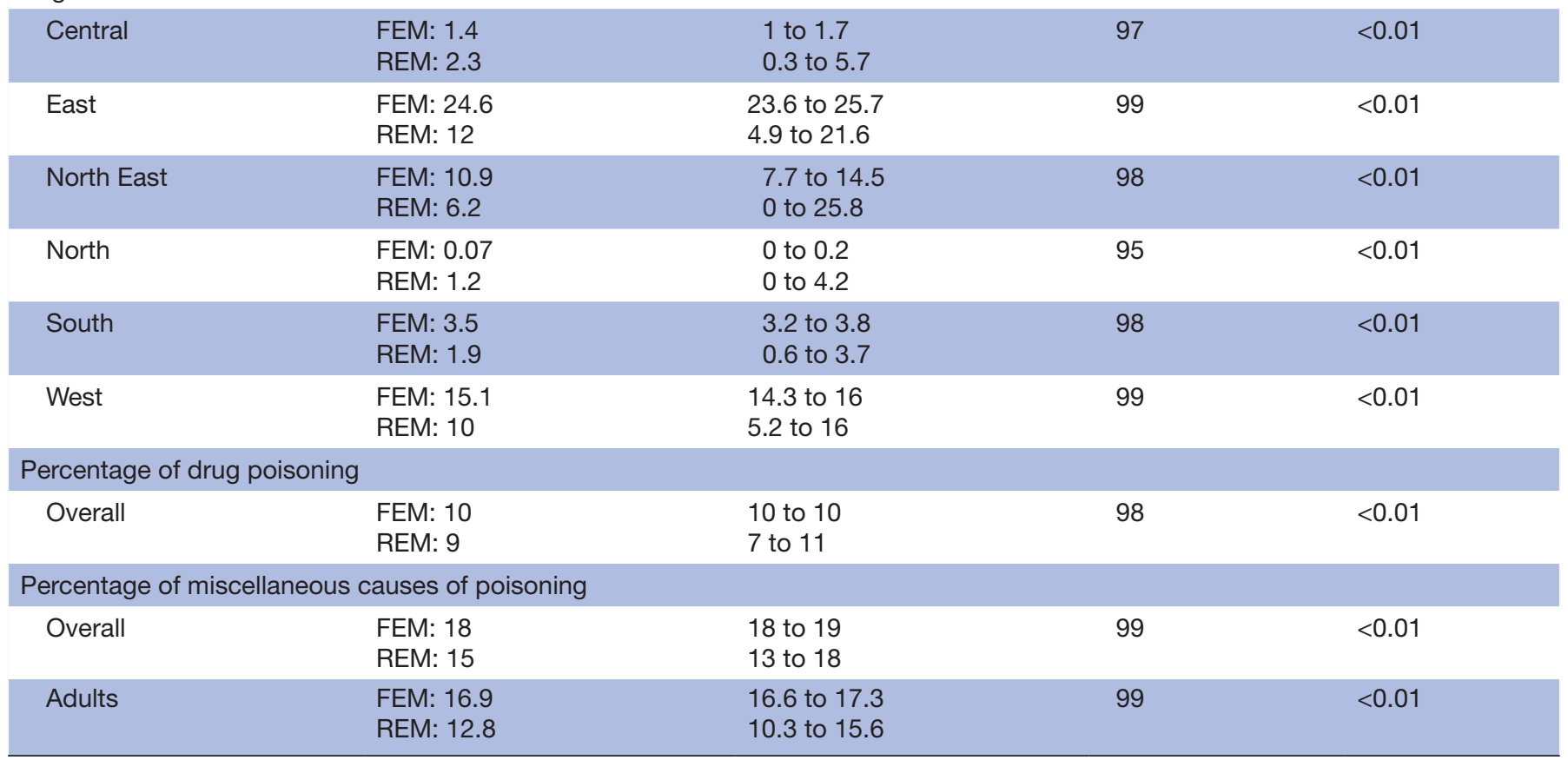

Continued 
Table 2 Continued

\begin{tabular}{cllcc}
\hline Outcome & \% of pooled data & $95 \%$ Cl & I $^{2}$ (\%) & P-value* \\
\hline Children & FEM: 45 & 43.1 to 46.9 & 94 & $<0.01$
\end{tabular}

Central region of Indian States: Chhattisgarh, Madhya Pradesh, Uttarakhand and Uttar Pradesh. Eastern region of Indian State: Bihar, Jharkhand, Odisha, and West Bengal. Northern region of Indian States: Chandigarh, Delhi, Haryana, Himachal Pradesh, Jammu and Kashmir, Ladakh, Punjab, and Rajasthan. North Eastern region of Indian States: Assam, Arunachal Pradesh, Manipur, Meghalaya, Mizoram, Nagaland, Sikkimand Tripura. Western region of Indian States: Dadra and Nagar Haveli and Daman and Diu, Goa, Gujarat, andMaharashtra. Southern region of Indian States: Andhra Pradesh, Karnataka, Kerala, Puducherry, Tamil Nadu, and Telangana. ${ }^{*} \mathrm{P}$-value for heterogeneity $\left(\mathrm{I}^{2}\right)$

FEM, fixed effect model; REM, random effect model.

the fixed effect and random effect models, respectively (online supplemental figure 2).

\section{Percentage of venom and drug poisoning}

Pooled analysis of studies revealed the cause of poisoning to be snakebites in $6 \%\left(95 \%\right.$ CI $6 \%$ to $6 \% ; \mathrm{I}^{2}=99 \%$, $\mathrm{p}<0.01$ ) of individuals presenting to hospitals, in the fixed effect model. In the random effect model, the prevalence of snakebite poisoning among individuals was around 3\% (95\% CI 2\% to 5\%) (online supplemental figure 2).

The fixed effect and random effect models predict the prevalence of drug poisoning among individuals at around $10 \%$ (95\% CI $10 \%$ to $\left.10 \% ; \mathrm{I}^{2}=98 \%, \mathrm{p}<0.01\right)$ and $9 \%$ (95\% CI $7 \%$ to $11 \%$ ), respectively (online supplemental figure 2).

\section{Percentage of miscellaneous causes of poisoning}

Pooled analysis of studies revealed poisoning with miscellaneous agents in $18 \%$ (95\% CI $18 \%$ to $19 \%$; $\mathrm{I}^{2}=99 \%$, $\mathrm{p}<0.01$ ) of individuals presenting to hospitals, in the fixed effect model. In the random effect model, the prevalence of poisoning due to miscellaneous agents among individuals was around $15 \%$ (95\% CI 13\% to 18\%) (online supplemental figure 3). In adults, miscellaneous agents are the second most common cause of poisoning in $16.9 \%$ (95\% CI $16.6 \%$ to $17.3 \%$ ) and $12.8 \%$ (95\% CI $10.3 \%$ to $15.6 \%$ ), in the fixed effect and random effect models. In children, miscellaneous agents are the most common cause of poisoning, responsible for $45.0 \%$ (95\% CI $43.1 \%$ to $\left.46.9 \% ; \mathrm{I}^{2}=99 \%, \mathrm{p}<0.01\right)$ and $39.6 \%(95 \%$ CI $12.7 \%$ to $18.1 \%$ ) of poisoning, with fixed and random effects, respectively (online supplemental figure 3 ).

\section{Subgroup analysis of corrosive and venom poisoning}

In adults, the prevalence of corrosive poisoning was $1.3 \%$ (95\% CI $1.1 \%$ to $\left.1.4 \% ; \mathrm{I}^{2}=95 \%, \mathrm{p}<0.01\right)$ and $1.7 \%$ (95\% CI $1.1 \%$ to $2.5 \%)$, in the fixed effect and random effect models. In children, the prevalence of corrosive poisoning was $10.8 \%$ (95\% CI $9.6 \%$ to $12 \%$; $\mathrm{I}^{2}=91 \%$, $\mathrm{p}<0.01$ ) and $11.2 \%$ (95\% CI $7.2 \%$ to $15.8 \%$ ), with fixed and random effects, respectively (online supplemental figure 4). The prevalence of venom poisoning in the east and west regions of India was $24.6 \%$ (95\% CI $23.6 \%$ to $25.7 \% ; \mathrm{I}^{2}=99 \%, \mathrm{p}<0.01$ ) and $15.1 \%$ (95\% CI $14.3 \%$ to $\left.16 \% ; \mathrm{I}^{2}=99 \%, \mathrm{p}<0.01\right)$, in the fixed effect model analysis (online supplemental figure 4). The fixed effect model analysis for other regions and the random effect results for all regions are shown in online supplemental figure 4. Venom poisoning was the most prevalent in East and West India compared with other parts of the country.

\section{Publication bias}

Publication bias was low, as the funnel plot of 134 studies appears to be asymmetrical around the intervention effect estimate for the percentage of individuals with pesticide poisoning (figure 2). We applied Egger's regression test for funnel plot asymmetry, which showed a value of $\mathrm{t}=0.9137$ and $\mathrm{p}=0.3609$, indicating low publication bias.

\section{DISCUSSION}

To delineate the trends of poisoning in India, a comprehensive analysis of various types of poisoning and their distribution among different age groups and regions is essential. Epidemiological data on poisoning available in India are either from government sources such as the National Crime Records Bureau (NCRB) or independent studies conducted at tertiary care hospitals. It has been observed that NCRB under-reports male and female deaths by around $25 \%$ and $36 \%$, respectively. ${ }^{3}$ Therefore, we conducted the current review to analyse the prevalence of various types of poisoning in India from published observational studies.

Suicidal deaths by intake of poisonous agents or by hanging constitute the leading cause of death among

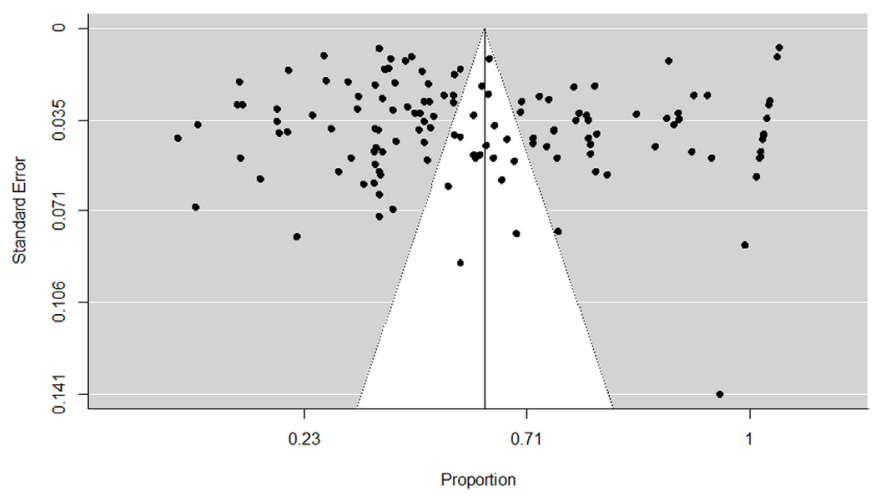

Figure 2 Publication bias. 
individuals between 15 and 39 years in India. ${ }^{13}$ Death by poisoning thus constitutes a major public health issue in India. ${ }^{14}$ Among poisoning agents, pesticides were the leading cause of poisoning, due to coexistence of poverty, agricultural farming and thus easy availability of pesticides, and the patriarchal society in India. ${ }^{15}$

The present review showed that the highly vulnerable age group was $19-40$ years (45\%). The results were similar to the study done by Kamaruzaman et $a l,{ }^{16}$ who concluded that about $44.6 \%$ of poisoned patients were aged between 20 and 39 years. However, Patel $e t a l^{3}$ observed that suicide was most common between 15 and 29 years of age. The difference may be due to the prospective cohort design of Patel $e t a l$ s study, ${ }^{3}$ while we pooled data from all types of observational studies. Young adults aged 19-40 years have financial and social responsibilities to their family as part of their social transformation. ${ }^{17}$

In our review, it was observed that the male to female ratio of the chances of exposure to poisoning was 1.7 times. We found higher male to female ratio than the study done by Patel et $a l^{\beta}$ (1.7 vs $\left.1-1.5\right)$. The possible reason for this is that we included all cases of poisoning, while Patel $e t a l^{3}$ included only suicide by poisoning. Several reasons for committing suicide by poisoning are suggested. Men and farmers of low socioeconomic status suffer from severe stress due to inability to cope with the expectations of a rapidly urbanising society. Expecting higher returns from commercial crops, small farmers take higher risks by taking loans which they are unable to pay as a result of being unable to sell crops at expected rates. Inability to support the family due to low income from farming often leads to increased rates of suicides among them. ${ }^{1819}$ In India, women move in with men after their marriage and have to adopt to new traditions, rituals and customs. ${ }^{20}$ This sort of migration and the prevalent patriarchal behaviour increase conflict and mistreatment of women. ${ }^{10}$ Factors such as family quarrels, dowry, cruelty by in-laws, etc, along with lack of an independent source of income among housewives, result in overdependence on men. ${ }^{21}{ }^{22}$ This leads to increased suicides by poison ingestion.

Pesticide poisoning is the most common type of poisoning, with an overall prevalence of $63 \%$ (two in every three cases of poisoning) and a prevalence of around $65 \%$ in adult population and $22 \%$ in children. Region-wise, the proportion of pesticide poisoning in North India is about $79 \%$ (more than three-fourths of the total cases of poisoning), $65 \%$ in South India, $60 \%$ in Central India, $53 \%$ in West India and less than $50 \%$ in East and North East India. The WHO and its member countries initiated a programme of safe access of pesticides, which has resulted in a decrease in the prevalence of fatal poisoning by $10 \%$ across the world. However, pesticides remain the leading cause of poisoning in South Asian countries including India and in South East Asia and China. ${ }^{123-25}$ Many studies have concluded that the strict restriction of highly lethal pesticides by legal mechanisms or policy actions drastically reduces deaths. ${ }^{82627}$
The pooled prevalence of corrosive poisoning in the whole population of India was found to be around $2 \%$ of the total cases of poisoning. In adult population it constitutes around $1.3 \%$ and in children around $10.8 \%$. The higher prevalence of corrosive poisoning in children may be due to their inquisitive nature, their tendency to explore household items containing corrosive cleaning agents. ${ }^{28}$ In the USA, corrosive ingestions constitute about $8 \%-9 \%$ of the total poisoning in all patients. ${ }^{29}$ This difference may be due to under-reporting of events in India. ${ }^{28}$

Snakebite remains a major challenge in rural India, as $71 \%$ of the total population live in rural India and primarily depend on agriculture for livelihood. ${ }^{30}$ The overall prevalence of venom poisoning in India is $6 \%$ of all cases of poisoning. Among all cases of envenomation $(6 \%)$, the eastern and western parts of India contribute around $24 \%$ and $15 \%$ of cases, respectively. We have observed the regional differences in envenomation may be due to the topography of the eastern and western ghats. The spatial distribution of cases was similar to the eastern part but not to the western part of India in the study done by Suraweera $e t a l .{ }^{31}$ This difference is due to exclusion of studies reporting only snakebites from our meta-analysis. ${ }^{31}$

Drug overdose constitutes about $10 \%$ of cases of poisoning in India and may possibly be due to easy availability of drugs and alcohol. In India, many prescription drugs are available over the counter. Although we have not performed sex-wise distribution of drug poisoning, evidence from the literature showed that women used drugs more commonly to commit suicide. ${ }^{17}$ In agricultural societies, men typically work in the field during daytime, whereas women look after household activities. Therefore, the choice of pesticides among men and drugs or chemicals among women may be partially explained by occupational proximity to different types of poisoning agents. $^{32}$

Miscellaneous agents account for $18 \%$ of all causes of poisoning. In children, its prevalence was $45 \%$ and in adults it was $16 \%$. The higher prevalence of poisoning among children is due to their exploratory behaviour leading to accidental ingestion. Negligence of parents and caretakers may also be a contributing factor. ${ }^{33-35}$ Poisoning among preschool or toddler age groups is primarily unintentional or accidental. In adolescents, it is mostly of suicidal nature. The most commonly used products were kerosene and sterilising agents. ${ }^{36-38}$

The purpose of the present study was primarily to determine the prevalence of various poisonous agents and their region-wise distribution. The overall observation is that men 19-40 years of age usually ingest pesticides intentionally, while housewives and children ingest drugs or miscellaneous agents intentionally or accidentally. Establishment of specialised toxicological units at all hospitals and primary healthcare centres to identify and manage cases of poisoning could considerably minimise the morbidity and mortality associated with poisoning. Similar to USA, India must develop a central database on 
national poisoning statistics for decentralised management of poisoning. Adequate preventive measures with stable employment opportunities and bridging the sociocultural gap between men and women, along with proper supervision and care of children, can reduce cases of poisoning in India.

\section{Strengths and limitations of this study}

The study provides a comprehensive overview of poisoning in India as analysed from observational studies published from January 2010 to May 2020. The results were represented as type, manner, demographic pattern and prevalence rate of various cases of poisoning, as well as persons at high risk of poisoning with particular agents. The data presented in this study may be under-reported as only moderate to severe poisoning cases report to hospitals. There was no analysis on the medical outcomes of patients, thereby restricting the scope of analysis.

\section{CONCLUSION}

Pesticides are the most common type of poisons ingested intentionally by adults especially by male farmers of rural India, while miscellaneous agents remain the main cause of poisoning in children. This information will be useful for the government of India in its decentralised and people-centric policy decisions to meet its target under the United Nations Sustainable Development Goals to substantially reduce illness and death due to poisoning.

Strict restriction of highly lethal pesticides by legal or policy actions drastically reduces deaths. Preventive measures must be developed for the high-risk groups identified in our study. Legislative control on the sale and use of pesticides and stress management are recommended, along with better healthcare facilities, to prevent poisoning-related death.

Contributors Study design and planning of systematic review: all authors. Literature search: SBV, CM, SS. Figures: PKM, SS. Tables: SBV, PKM, CM. Data collection and analysis: SS, SBV, PKM. Data interpretation: SS, CM, SBV, PKM. Writing: all authors. Corrections and final approval of the manuscript: all authors.

Funding The authors have not declared a specific grant for this research from any funding agency in the public, commercial or not-for-profit sectors.

Competing interests None declared.

Patient consent for publication Not required.

Provenance and peer review Not commissioned; externally peer reviewed.

Data availability statement Data are available upon reasonable request. The datasets used and/or analysed in the current study are available from the corresponding author on request.

Supplemental material This content has been supplied by the author(s). It has not been vetted by BMJ Publishing Group Limited (BMJ) and may not have been peer-reviewed. Any opinions or recommendations discussed are solely those of the author(s) and are not endorsed by BMJ. BMJ disclaims all liability and responsibility arising from any reliance placed on the content. Where the content includes any translated material, BMJ does not warrant the accuracy and reliability of the translations (including but not limited to local regulations, clinical guidelines, terminology, drug names and drug dosages), and is not responsible for any error and/or omissions arising from translation and adaptation or otherwise.
Open access This is an open access article distributed in accordance with the Creative Commons Attribution Non Commercial (CC BY-NC 4.0) license, which permits others to distribute, remix, adapt, build upon this work non-commercially, and license their derivative works on different terms, provided the original work is properly cited, appropriate credit is given, any changes made indicated, and the use is non-commercial. See: http://creativecommons.org/licenses/by-nc/4.0/.

ORCID iDs

Surjit Singh http://orcid.org/0000-0002-8990-3235

Shoban Babu Varthya http://orcid.org/0000-0002-7163-0400

\section{REFERENCES}

1 World Health Organization. World health statistics 2016: monitoring health for the SDGs sustainable development goals; 2016.

2 World Health Organization. Suicide key facts, 2019. Available: https:// www.who.int/news-room/fact- sheets/detail/suicide [Accessed 01 Oct 2019].

3 Patel V, Ramasundarahettige C, Vijayakumar L, et al. Suicide mortality in India: a nationally representative survey. Lancet 2012;379:2343-51.

4 Ahuja $\mathrm{H}$, Mathai AS, Pannu A, et al. Acute poisonings admitted to a tertiary level intensive care unit in northern India: patient profile and outcomes. J Clin Diagn Res 2015;9:UC01-4.

5 Blanchard J, Feltes M, Kim JY, et al. Experience of Indian emergency physicians in management of acute poisonings. Toxicol Commun 2019;3:54-60.

6 World Health Organization (WHO). Snakebite envenoming - A strategy for prevention and control. WHO Neglected tropical diseases/Snakebites reference number: 9789241515641, 2019c. Available: https://apps.who.int/iris/bitstream/handle/10665/324838/ 9789241515641-eng.pdf?ua $=1$ [Accessed 12 Apr 2021].

7 Srinivasulu K, Pratik KV, Reddy TR, et al. Study on profile of acute poisoning in a rural tertiary care hospital in Telangana. Medico-Legal Update 2019;19:84-8.

8 Mann JJ, Apter A, Bertolote J, et al. Suicide prevention strategies: a systematic review. JAMA 2005;294:2064-74.

9 Gunnell D, Eddleston M. Suicide by intentional ingestion of pesticides: a continuing tragedy in developing countries. Int $J$ Epidemiol 2003;32:902-9.

10 Chelkeba L, Mulatu A, Feyissa D, et al. Patterns and epidemiology of acute poisoning in Ethiopia: systematic review of observational studies. Arch Public Health 2018;76:34.

11 Varthya SB, Mittal C, Singh S. Comprehensive analysis of incidence and prevalence of poisoning in India and its regions: a systematic review and meta-analysis. Prospero CRD42020199427, 2020. Available: https://www.crd.york.ac.uk/prospero/display_record.php? ID=CRD42020199427

12 Schünemann H, Brożek J, Guyatt G. Grade Handbook for grading quality of evidence and strength of recommendations. The grade Working group, 2013. guidelinedevelopment.org/handbook

13 India State-Level Disease Burden Initiative Suicide Collaborators. Gender differentials and state variations in suicide deaths in India: the global burden of disease study 1990-2016. Lancet Public Health 2018;3:e478-89.

14 Bonvoisin T, Utyasheva L, Knipe D, et al. Suicide by pesticide poisoning in India: a review of pesticide regulations and their impact on suicide trends. BMC Public Health 2020;20:251.

15 Radhakrishnan R, Andrade C. Suicide: an Indian perspective. Indian J Psychiatry 2012;54:304-19.

16 Kamaruzaman NA, Leong Y-H, Jaafar MH, et al. Epidemiology and risk factors of pesticide poisoning in Malaysia: a retrospective analysis by the National poison centre (NPC) from 2006 to 2015. BMJ Open 2020;10:e036048.

17 Dash SK, Sitarama Raju A, Mohanty MK. Sociodemographic profile of poisoning cases. Journal of indian academy of forensic medicine 2005;27:133-8.

18 Singh O, Javeri Y, Juneja D, et al. Profile and outcome of patients with acute toxicity admitted in intensive care unit: experiences from a major corporate hospital in urban India. Indian J Anaesth 2011;55:370-4

19 Siwach SB, Gupta A. The profile of acute poisonings in HarayanaRohtak study. J Assoc Physicians India 1995;43:756-9.

20 Kora SA, Doddamani GB, Halagali GR. Sociodemographic profile of the organophosphorus poisoning cases in southern India. Journal of clinical diagnostic Research 2011;5:953-6.

21 Karikalan T, Murugan M. Profile of poisoning cases in a tertiary care Hospital, Tamilnadu. Journal of Evolution of Medical Dental Sciences 2014;3:12754-61. 
22 Vijayakumari N. Profile of poisoning cases in a tertiary care Hospital, Tamil Nadu, India. J Appl Pharm Sci 2013;3:91.

23 World Health Organization. Preventing suicide: a global imperative; 2014

24 Eddleston M, Karalliedde L, Buckley N, et al. Pesticide poisoning in the developing world--a minimum pesticides list. Lancet 2002;360:1163-7.

25 Mew EJ, Padmanathan P, Konradsen F, et al. The global burden of fatal self-poisoning with pesticides 2006-15: systematic review. $J$ Affect Disord 2017;219:93-104.

26 Barber CW, Miller MJ. Reducing a suicidal person's access to lethal means of suicide: a research agenda. Am J Prev Med 2014;47:S264-72.

27 Yip PSF, Caine E, Yousuf S, et al. Means restriction for suicide prevention. Lancet 2012;379:2393-9.

28 Lakshmi CP, Vijayahari R, Kate V, et al. A hospital-based epidemiological study of corrosive alimentary injuries with particular reference to the Indian experience. Natl Med J India 2013;26:31-6.

29 Bronstein AC, Spyker DA, Cantilena LR, et al. 2008 annual report of the American association of poison control centers' national poison data system (NPDS): 26th annual report. Clin Toxicol 2009;47:911-1084.

30 Census of India. Available: http://www.censusindia.gov.in/ DigitalLibrary/MFTableSeries.aspx [Accessed 4 Dec 2019].
31 Suraweera W, Warrell D, Whitaker R, et al. Trends in snakebite deaths in India from 2000 to 2019 in a nationally representative mortality study. Elife 2020;9. doi:10.7554/eLife.54076. [Epub ahead of print: 07 07 2020].

32 Benjamin RN, David T, lyadurai R, et al. Suicidal Nonorganophosphate poisoning in a tertiary hospital in South India: nature, prevalence, risk factors. Indian J Psychol Med 2018;40:47-51.

33 Kanchan T, Menezes RG, Kumar TSM, et al. Toxicoepidemiology of fatal poisonings in southern India. J Forensic Leg Med 2010;17:344-7.

34 Shirkosh S, Esmaeilidooki M, Nakhjavani N. Epidemiological and clinical pattern of acute poisoning in children: a hospital based study in northern Iran. Caspian Journal of Pediatrics 2019;5:334-41.

35 Naseem DA, Khurram DMSA, Khan DSS, et al. Accidental poisoning its magnitude and implications in children. Int $J$ Pediatr Res 2016;3:400-9.

36 Saikia D, Sharma RK, Janardhan KV. Clinical profile of poisoning due to various poisons in children of age 0-12 years. J Family Med Prim Care 2020;9:2291.

37 Brata Ghosh V, Jhamb U, Singhal R, et al. Common childhood poisonings and their outcome in a tertiary care center in Delhi. Indian $J$ Pediatr 2013;80:516-8.

38 Rathore S, Verma AK, Pandey A. Pediatric poisoning trend in Lucknow district, India. J Forensic Res 2013;4:179-80. 